\title{
Production and purification of recombinant xylanases for application in juice clarification
}

\author{
Amanda Tafuri Paniago Passarinho ${ }^{1^{*}}$, Mariana Siqueira Lacerda \\ Mamede $^{2}$, Eduardo Basílio de Oliveira ${ }^{3}$, Valeria Monteze Guimaraes ${ }^{2}$ \\ ${ }^{I}$ Núcleo de Pesquisas em Ciências Biológicas, Universidade Federal de Ouro Preto, Ouro Preto/MG \\ ${ }^{2}$ Departamento de Bioquímica e Biologia Molecular, Universidade Federal de Viçosa, Viçosa/MG \\ ${ }^{3}$ Departamento de Tecnologia de Alimentos, Universidade Federal de Viçosa, Viçosa/MG \\ *e-mail: amandatpp@gmail.com
}

\section{Abstract}

Endo- $\beta$-1,4-xylanases (EC 3.2.1.8) are able to hydrolyse xylan, the second most abundant polysaccharide in plant cell walls. In this work, two recombinant xylanases derived from Orpinomyces xynA gene were studied: one with mutations A226T and V135A (XM) and the other without mutations (XNM). They have been cloned in E. coli/pET24b, using IPTG as inducer and purified using ion exchange chromatography (Q-Sepharose). After purification, only one band of $25 \mathrm{kDa}$, corresponding to xylanases, was visualized on SDS-PAGE. Specific activities and $\mathrm{Km}$ against arabinoxylan were $12.844 \mathrm{U} \cdot \mathrm{mg}^{-1}$ and 0.0021 mg.mL ${ }^{-1}$ for XNM and $10.794 \mathrm{U}_{\mathrm{Jgg}} \mathrm{m}^{-1}$ and $0.0014 \mathrm{mg} \cdot \mathrm{mL}^{-1}$ for XM. The mutations improve thermo stability. The half-life of XNM was $220 \mathrm{~min}$ and 31 min at $50{ }^{\circ} \mathrm{C}$ and $60{ }^{\circ} \mathrm{C}$, while for $\mathrm{XM}$ the values were 440 and $71 \mathrm{~min}$ at $50{ }^{\circ} \mathrm{C}$ and $60{ }^{\circ} \mathrm{C}$, respectively. The clarification assays were conducted at $60{ }^{\circ} \mathrm{C}, 100$ rpm for $60 \mathrm{~min}$, using $50 \mathrm{U}$ xylanase $/ \mathrm{mL}$ apple juice. The parameters available was $\mathrm{pH}, \mathrm{A} 660$ (clarity), L* (luminosity), C (chroma) and $\mathrm{h}^{*}$ (hue). All the juices tended to orange while only enzymatically treated with XM had an increase in color intensity (chroma / C) and higher content of soluble solids (sst) of 4,7 ${ }^{\circ}$ brix. The results indicate that the processing of apple juice with xylanases can promote clarification and improvement of its properties.

Palavras-chave: xylanase, juice clarification, apple

Apoio financeiro: CNPq, FAPEMIG, CAPES, Bioagro/UFV 